Supporting Information

\title{
Synthesis of $\mathbf{N}, \mathbf{O}$-doped porous graphene from petroleum coke for
}

\section{deep oxidative desulfurization of fuel}

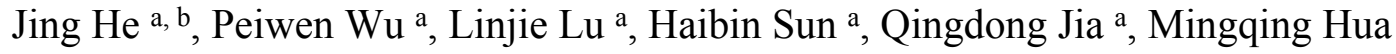
a, Minqiang $\mathrm{He}^{\mathrm{a}}$, Chunjuan $\mathrm{Xu}^{\mathrm{c}}$, Wenshuai $\mathrm{Zhu}{ }^{\mathrm{a}, *}$, Huaming $\mathrm{Li}^{\mathrm{d}}{ }^{\mathrm{*}}$ *

a School of Chemistry and Chemical Engineering, Jiangsu University, Zhenjiang, Jiangsu, 212013, P. R. China

${ }^{\mathrm{b}}$ School of the Environment and Safety Engineering, Jiangsu University, Zhenjiang, Jiangsu, 212013, P. R. China

${ }^{\mathrm{c}}$ Zhenjiang carbon products co. LTD, Zhenjiang, Jiangsu, 212013, 3, P. R. China

${ }^{d}$ Institute for Energy Research, Jiangsu University, Zhenjiang, Jiangsu, 212013, P.

R. China

*E-mail: zhuws@ujs.edu.cn (W. S. Zhu); lihm@ujs.edu.cn (H. M. Li). 


\section{Captions:}

Table S1. The metal element analysis of as-prepared catalyst.

Table S2. The XPS peaks information of PG materials.

Table S3. The element analysis of as-prepared catalyst.

Table S4. Adsorption capacities of as-prepared samples.

Figure S1. The controlling experiment of no catalyst for ODS.

Figure S2. TEM image of PG-450.

Figure S3. The XPS characterizations of Graphite- 450 .

Figure S4. Analysis of the used catalyst by XRD patterns.

Figure S5. Analysis of the used catalyst by TG-DSC patterns. 
Table S1. The metal element analysis of as-prepared catalyst.

\begin{tabular}{ccccccc}
\hline Sample & \multicolumn{2}{l}{ Metal element (\%) } & & & & \\
\cline { 2 - 7 } & $\mathbf{M g}$ & $\mathbf{N a}$ & $\mathbf{K}$ & $\mathbf{C a}$ & $\mathbf{F e}$ & $\mathbf{Z n}$ \\
\hline PG-15 & 0.34 & 0.63 & 0.21 & 0.37 & 0.07 & 0.05 \\
PG-450 & 0.38 & 0.69 & 0.21 & 0.32 & 0.10 & 0.04 \\
\hline
\end{tabular}

The metal element in PG is analyzed by electron-coupled plasma atomic emission spectrum (ICP-AES). the result shows that trace amounts of metal elements are present in the material and its content is basically kept constant.

Table S2. The XPS peaks information of PG materials.

\begin{tabular}{lcll}
\hline Sample & graphite-like N & pyrrolic N & pyridinic N \\
\hline PG-15 & $37.2 \%$ & $27.1 \%$ & $35.7 \%$ \\
PG-450 & $47.8 \%$ & $26.4 \%$ & $25.8 \%$ \\
\hline
\end{tabular}

Table S3. The element analysis of as-prepared catalyst.

\begin{tabular}{llll}
\hline Sample & $\mathbf{C}(\%)$ & $\mathbf{N}(\%)$ & $\mathbf{O}(\%)$ \\
\hline PG-450 & 74.8 & 4.9 & 19.9 \\
Graphite-450 & 82.2 & 1.2 & 16.5 \\
\hline
\end{tabular}


Table S4. Adsorption capacities of as-prepared samples.

\begin{tabular}{ccccc}
\hline Entry & Samples & $C_{0}(\mathrm{ppm})$ & $C_{e}(\mathrm{ppm})$ & $q_{e}\left(\mathrm{mg} \mathrm{g}^{-1}\right)$ \\
\hline 1 & PG-450 & 487.0 & 453.5 & 13.5 \\
\hline
\end{tabular}

Experimental conditions: $m(\mathrm{PG}-450)=0.0248 \mathrm{~g}, T=25^{\circ} \mathrm{C}, V($ oil, DBT $)=10$

$\mathrm{mL}, t=30 \mathrm{~min}$, atmospheric pressure. 


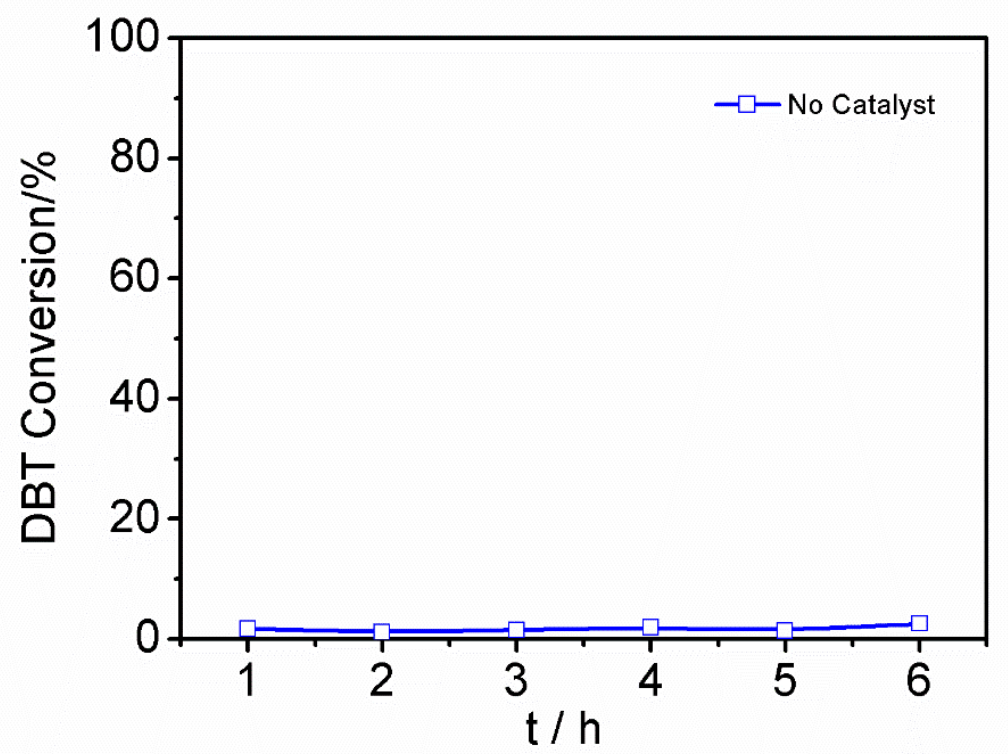

Figure S1. The controlling experiment of no catalyst for ODS.

Experimental conditions: $T=120^{\circ} \mathrm{C}, V$ (oil, 200 ppm of S) $=20 \mathrm{~mL}, v($ air $)=100$ $\mathrm{mL} \min ^{-1}$. 

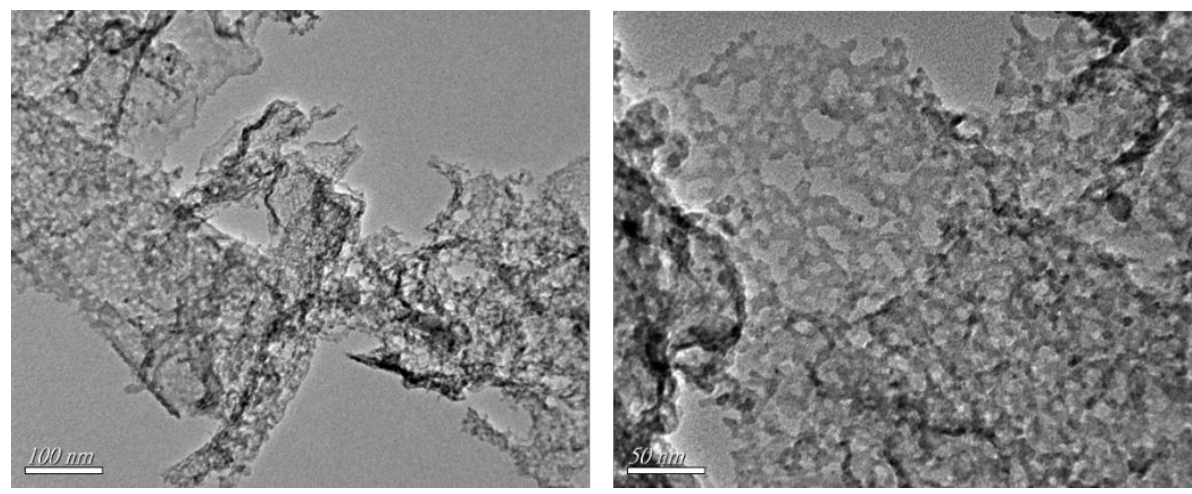

Figure S2. TEM image of PG-450. 

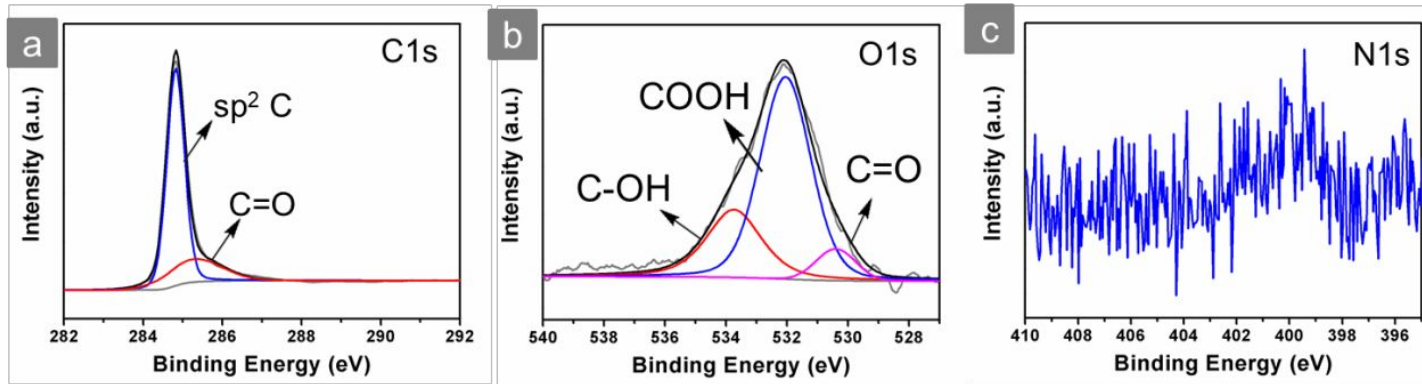

Figure S3. The XPS characterizations of Graphite-450. (a) Fitted C1s XPS spectra of Graphite-450. (b) Fitted O1s XPS spectra of Graphite-450. (c) N1s XPS spectra of Graphite-450. 


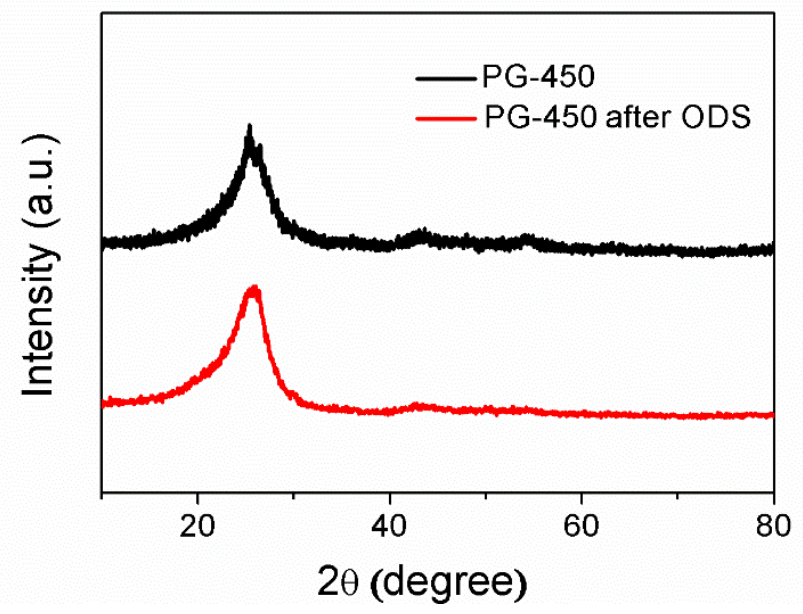

Figure S4. Analysis of the used catalyst by XRD patterns. 


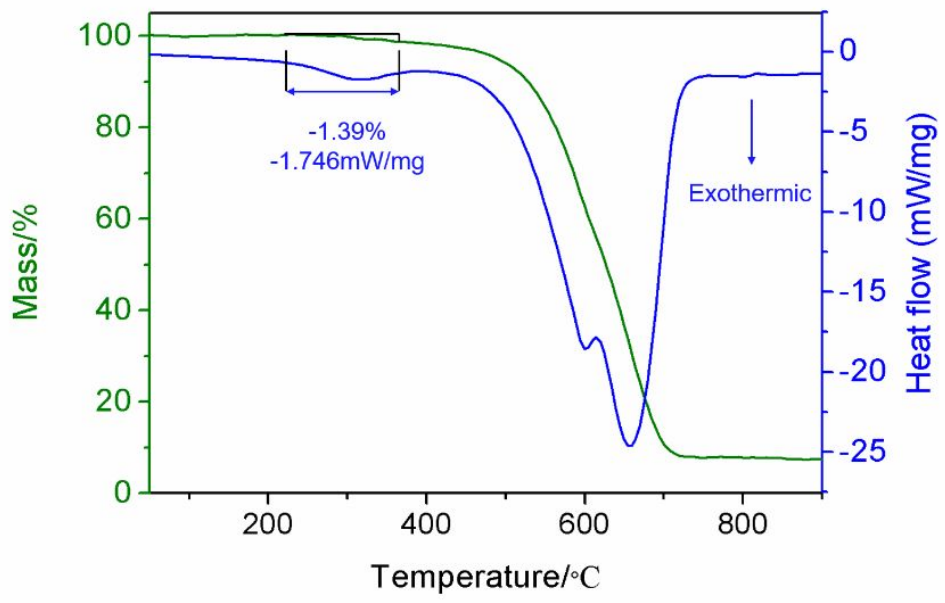

Figure S5. Analysis of the used catalyst by TG-DSC patterns. 